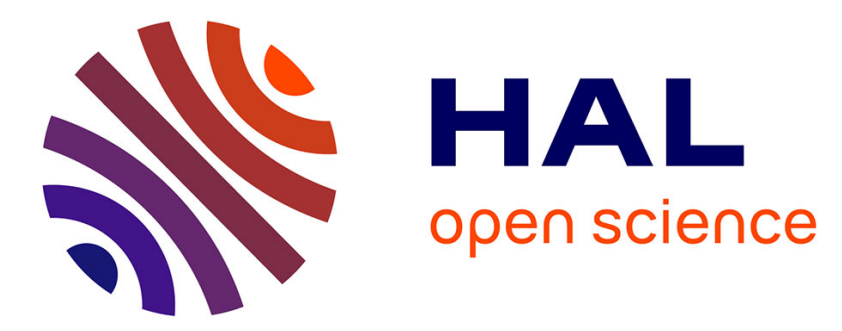

\title{
Systematic review of aromatase inhibitors in the first-line treatment for hormone sensitive advanced or metastatic breast cancer
}

Rob Riemsma, C. A. Forbes, A. Kessels, K. Lykopoulos, M. M. Amonkar, D. W. Rea, J. Kleijnen

\section{To cite this version:}

Rob Riemsma, C. A. Forbes, A. Kessels, K. Lykopoulos, M. M. Amonkar, et al.. Systematic review of aromatase inhibitors in the first-line treatment for hormone sensitive advanced or metastatic breast cancer. Breast Cancer Research and Treatment, 2010, 123 (1), pp.9-24. 10.1007/s10549-010-0974-0 . hal-00545276

\section{HAL Id: hal-00545276 \\ https://hal.science/hal-00545276}

Submitted on 10 Dec 2010

HAL is a multi-disciplinary open access archive for the deposit and dissemination of scientific research documents, whether they are published or not. The documents may come from teaching and research institutions in France or abroad, or from public or private research centers.
L'archive ouverte pluridisciplinaire HAL, est destinée au dépôt et à la diffusion de documents scientifiques de niveau recherche, publiés ou non, émanant des établissements d'enseignement et de recherche français ou étrangers, des laboratoires publics ou privés. 


\title{
Systematic review of aromatase inhibitors in the first-line treatment for hormone sensitive advanced or metastatic breast cancer
}

\author{
Rob Riemsma • C. A. Forbes $\cdot$ A. Kessels • \\ K. Lykopoulos • M. M. Amonkar • D. W. Rea • \\ J. Kleijnen
}

Received: 1 April 2010/Accepted: 29 May 2010/Published online: 10 June 2010

(C) Springer Science+Business Media, LLC. 2010

\begin{abstract}
To undertake a systematic review of three firstline treatments (letrozole, anastrozole and exemestane) for hormone sensitive advanced or metastatic breast cancer (MBC) in post-menopausal women. We searched six databases from inception up to January 2009 for relevant trials regardless of language or publication status. Randomised controlled clinical trials assessing the safety and efficacy of first-line AIs for post-menopausal women with hormone receptor-positive $(\mathrm{HR}+$, i.e. $\mathrm{ER}+$ and/or $\mathrm{PgR}+)$ with or without ErbB2 (HER2)-positive MBC, who have not received prior therapy for advanced or metastatic disease were included. Where meta-analysis using direct or indirect comparisons was considered unsuitable for some or all of the data, we employed a narrative synthesis method. Four studies (25 papers) met the inclusion criteria. From the available evidence, it was possible to directly compare the three AIs with tamoxifen. In addition, by using a network meta-analysis it was possible to compare the three AIs with
\end{abstract}

R. Riemsma ( $₫) \cdot$ C. A. Forbes · J. Kleijnen

Kleijnen Systematic Reviews Ltd., Unit 6, Escrick Business

Park, Riccall Road, Escrick, York YO19 6FD, UK

e-mail: rob@systematic-reviews.com

A. Kessels · J. Kleijnen

School for Public Health and Primary Care (CAPHRI),

Maastricht University, Maastricht, The Netherlands

K. Lykopoulos

GlaxoSmithKline, Brentford, UK

M. M. Amonkar

GlaxoSmithKline, Philadelphia, PA, USA

D. W. Rea

Institute for Cancer Studies, University of Birmingham,

Birmingham, UK each other. Based on direct evidence, letrozole seemed to be significantly better than tamoxifen in terms of time-toprogression (TTP) $(\mathrm{HR}=0.70(95 \% \mathrm{CI}: 0.60,0.82)$ ), objective response rate $(\mathrm{RR}=0.65(95 \% \mathrm{CI}: 0.52,0.82))$ and quality-adjusted time without symptoms or toxicity (QTwist difference $=1.5 ; P<0.001$ ). Exemestane seemed significantly superior to tamoxifen in terms of objective response rate $(\mathrm{RR}=0.68$ (95\% CI: $0.53,0.89)$ ). Anastrozole seemed significantly superior to tamoxifen in terms of TTP in one trial $(\mathrm{HR}=1.42(95 \% \mathrm{CI}: 1.15, \mathrm{NR}))$, but not in the other $(\mathrm{HR}=1.01$ (95\% CI: 0.87, NR)). In terms of adverse events, no significant differences were found between letrozole and tamoxifen. Tamoxifen was associated with significantly more serious adverse events in comparison with exemestane (OR $=0.61$ (95\% CI: 0.38, 0.97)); while exemestane was associated with significantly more arthralgia in comparison with tamoxifen $(\mathrm{OR}=2.33$ (95\% CI: 1.07, 5.11)). Anastrozole was associated with significantly more total adverse events $(\mathrm{OR}=1.04(95 \%$ CI: $1.00,1.09)$ ) and hot flushes (OR $=1.39$ (95\% CI: 1.03 , 1.89)) in comparison with tamoxifen in one trial; however, the other trial showed no significant differences in adverse events between anastrozole and tamoxifen. The indirect comparison of AIs with each other in women with postmenopausal, hormone sensitive advanced or MBC showed that letrozole and exemestane were better in terms of objective response rate than anastrozole; while the more clinically relevant outcomes overall survival (OS) and progression-free survival (PFS) showed no significant differences between AIs. OS and PFS showed no significant differences between AIs and hence based on these results a class effect for all AIs is possible. However, these results are based on indirect comparisons and a network analysis for which the basic assumptions of homogeneity, similarity and consistency were not fulfilled. Therefore, despite the 
fact that these are the best available data, the results need to be interpreted with appropriate caution. Head-to-head comparisons between letrozole, anastrozole and exemestane in the first-line MBC setting are warranted.

Keywords Systematic review - Aromatase inhibitors . First-line treatment $\cdot$ Hormone sensitive advanced or metastatic breast cancer

\section{Introduction}

Breast cancer is the most common cancer affecting women in the western world accounting for nearly 1 in 3 of all cancers in women. In England and Wales with a population of approximately 50 million, over 40,000 new cases were diagnosed in 2006 [1], and there were over 11,000 deaths due to breast cancer in 2007 [2].

Between 16 and $20 \%$ of women in the UK presenting with breast cancer have advanced disease with distant metastases. In the past, $50 \%$ of those presenting with early or localised breast cancer eventually developed metastatic breast cancer (MBC) [3]. However, outcomes in early breast cancer have been steadily improving over the last 20 years with a marked decline in breast cancer mortality despite increasing incidence. $75 \%$ of breast cancers express oestrogen receptors and are potentially sensitive to endocrine manipulation to reduce the oestrogenic stimulus to proliferation.

Oestrogen depravation or antagonism are the two most commonly used approaches. The most impressive effects are seen in the context of early disease where use of adjuvant endocrine therapy with tamoxifen has a profound impact on breast cancer mortality [4]. Adjuvant endocrine therapy is widely believed to be the most important single factor responsible for the recent decline in breast cancer mortality. In the advanced disease setting, endocrine therapy for ER-positive disease offers a comparatively low toxicity treatment option for disease control [5]. In patients unsuitable for cytotoxic chemotherapy endocrine therapy is often the only systemic treatment option available.

Not all ER-positive tumours are sensitive to endocrine manipulation and the degree of sensitivity is variable in terms of degree of tumour shrinkage and duration of effect before resistance invariably emerge, thus endocrine therapy for advanced disease offers palliation but not cure. In addition to tumour regression, endocrine therapy may simply arrest or slow the degree of tumour growth delaying the onset of new symptoms and thus preserving quality of life. This group is by convention identified in clinical trials as disease which remains stable for more than 6 months. In the past, choice of endocrine agents has focused on tolerability; however, it has become apparent more recently that clinical benefit in terms of tumour response tumour stabilisation and duration of these benefits differs between endocrine agents [6].

Tamoxifen was for many years the most widely used first-line hormonal therapy for post-menopausal patients with hormone sensitive advanced or MBC. Aromatase inhibitors (AIs), which have shown superior efficacy in advanced disease compared with tamoxifen have now largely replaced tamoxifen as first-line therapy in postmenopausal women [5]. In this context, however, they have been insufficiently explored in head-to-head trials in the firstline setting. Letrozole, anastrozole and exemestane are very specific and potent inhibitors of aromatase and are classed as third generation AIs and are all licensed for the treatment of breast cancer in a variety of both early and advanced disease settings. Letrozole and anastrazole are competitive inhibitors of aromatase with letrozole a more potent compound [7, 8]. Exemestane is a steroidal inhibitor and bonds irreversibly to the aromatase enzyme. The clinical significance of these biochemical differences between these drugs, however, remains uncertain.

Approximately $20 \%$ of breast cancers over-express a receptor known as human epidermal growth factor receptor 2 (HER2, synonymous with ErbB2) and are associated with poor prognosis and reduced overall survival (OS). The average survival after diagnosis of advanced or MBC is 18-24 months. This has been observed to be reduced by up to $50 \%$ for patients with tumours over-expressing HER2 [9]. Approximately, 15 to $20 \%$ of women with MBC have tumours which over-express HER2 at the $3+$ level measured by an immunohistochemical technique [3]. In recent years, however, this association of HER-2 positivity and poor survival appears to have changed and is likely to have been influenced by treatment with HER-2 targeted therapies [10]. Recent reports have highlighted the poor outcome for ER-positive HER-2-positive MBC treated with AIs alone and in this context there is considerable interest in the use of combination therapy using both ER and HER2 targeted therapy [11, 12].

In this report, our aim was to undertake a comprehensive systematic review of three first-line treatments (letrozole, anastrozole and exemestane) for hormone sensitive (i.e. oestrogen receptor-positive or unknown) advanced or MBC in post-menopausal women.

\section{Methods}

Inclusion criteria

We included randomised controlled clinical trials assessing the safety and efficacy of letrozole, anastrozole and 
exemestane for first-line treatment of post-menopausal women with hormone receptor-positive $(\mathrm{HR}+$, i.e. $\mathrm{ER}+$ and/or $\mathrm{PgR}+$ ) with or without ErbB2 (HER2)-positive $\mathrm{MBC}$, who have not received prior therapy for advanced or metastatic disease.

\section{Literature searches}

We attempted to identify all relevant trials regardless of language or publication status (published, unpublished, in press, and in progress). The search strategies (keywords) were developed specifically for each database (see Appendix 1). We searched the following databases from inception up to January 2009: MEDLINE, EMBASE, CDSR, CENTRAL, DARE and HTA.

Furthermore, references in retrieved articles and systematic reviews were checked, and the internet was searched via Google for relevant studies. Also the websites of licensing agencies and HTA agencies were checked. Identified references were downloaded in Reference Manager Software for further assessment and handling.

Methods of trial selection, quality assessment and data extraction

\section{Trial selection}

Two reviewers independently inspected the title and abstract of each identified reference. For potentially relevant articles, or in cases of disagreement, a copy of the full article was obtained, and inspected in further detail. Any disagreements were resolved through discussion.

\section{Assessment of methodological quality}

We used the Cochrane Collaboration quality assessment checklist [13]. Quality assessment was carried out independently by two reviewers. Any disagreements were resolved by consensus. The results of the quality assessment were used for descriptive purposes to provide an evaluation of the overall quality of the included studies and to provide a transparent method of recommendation for design of any future studies. In addition, we planned if enough data were available from the included studies, to include each of the quality components as explanatory variables in a meta-regression analysis to investigate potential sources of heterogeneity. However, this was not possible due to the limited number of studies per comparison. Findings from the quality assessment were also used to make recommendations for the conduct of future studies.

\section{Data collection}

For each study, data were extracted independently by two reviewers. Any disagreements were resolved by consensus.

Dichotomous data were extracted as the number of individuals with the outcome of interest and the total numbers of individuals in the intervention and control group. Continuous data were extracted as the mean and standard deviation (SD) for the intervention and control group. Survival data were extracted as the hazard ratio and its standard error. Where necessary, we used the formula (upper limit of the $95 \%$ CI minus lower limit of the $95 \%$ CI) divided by 3.92 to estimate the standard error from the 95\% CI, as recommended in the Cochrane Handbook [13].

\section{Data synthesis}

Where meta-analysis was considered unsuitable for some or all of the data, we employed a narrative synthesis method. This involved the use of narrative text and tables to summarise data to allow the reader to consider outcomes in the light of differences in study designs and potential sources of bias for each of the studies being reviewed.

However, where possible we used the following quantitative methods:

Dichotomous data were analysed by calculating the relative risk (RR) for each trial using the DerSimonian and Laird's method and the corresponding 95\% confidence intervals or the odds ratio (OR) using the Mantel-Haenszel method. Continuous data were analysed using the (weighted) mean difference between groups and the corresponding $95 \%$ confidence interval. Survival data were analysed by using the hazard ratio (HR) and its standard error (estimated as described above from the $95 \%$ CI where not given in the original paper).

We anticipated that systematic differences between studies (heterogeneity) would be likely. Therefore, the random effects model was used for the calculation of relative risks or weighted mean differences. Heterogeneity was initially assessed by measuring the degree of inconsistency in the studies' results $\left(I^{2}\right)$. This measure $\left(I^{2}\right)$ describes the percentage of total variation across studies that is due to heterogeneity rather than the play of chance. The value of $I^{2}$ lies between 0 and $100 \%$, and a simplified categorization of heterogeneity could be low, moderate, and high to $I^{2}$ values of 25,50 and $75 \%$.

In the event of important heterogeneity we intended to formally investigate potential causes using meta-regression; however, this was not possible because results of only two studies could be pooled.

Indirect comparisons providing comparisons between the three AIs and comparator treatments employed methods and principles as described by Bucher et al. [14], both 
for "narrative" indirect comparisons and for statistical indirect comparisons. These comparisons were employed for single outcomes as available. More complex "network meta-analysis" were done using the methods as described by Puhan et al. [15].

Sub-group analysis Initial plans to conduct subgroup analyses to investigate whether the efficacy differs according to: age group, performance status, prior therapy, extent of disease and location of metastases were not possible due to the limited number of studies per comparison.

\section{Results}

Literature searches for the review were performed in January 2009 and yielded 3,264 titles and abstracts. After screening for potential relevance, we ordered and assessed 274 full papers for possible inclusion and 29 references found through hand searching. From these, 25 papers (reporting data for 4 unique studies) met the inclusion criteria (Fig. 1). A further 13 papers [16-28] described a combined analysis of two included trials (Nabholtz [29] and Bonneterre [30]); these papers were used for information not reported in the original publications.

The full network included 4 unique studies comparing tamoxifen $(20 \mathrm{mg} /$ day) to letrozole [31-40], anastrozole (TARGET [30, 41-43] and North American [29, 44] studies), and exemestane [45-52]. One study comparing anastrozole to tamoxifen ( $40 \mathrm{mg} / \mathrm{day}$ ) [53] was excluded because the dosage was incomparable to dosages of tamoxifen used in the other studies.

Overall, the methodological quality of the studies was good and the majority of assessment criteria were fulfilled (see Appendix 2). Computer-generated randomisation methods were used in three studies, and only one study failed to report the methods used [45]. Similarly, concealment of allocation was used in three studies with only one study failing to adequately report their methods (PO25) [31]. One study adequately reported using double-blind methods, a further two studies reported that a double-blind design was used but did not adequately report their methods (Nabholtz [29] and Bonneterre [30]) and the final study used an open-label design [45]. All of the studies were free of the suggestion of selective outcome reporting and other problems which might suggest a risk of bias. Withdrawals and dropouts were also adequately reported in all four studies and intention-to-treat (ITT) analyses performed; however, one study failed to include all randomised participants in the ITT analysis [45].

An overview of all available comparisons is presented in Fig. 2. From this overview, we can see that tamoxifen can be directly compared with all three AIs, and that an indirect comparison using the Bucher method is possible between individual AIs. Using a network meta-analysis all treatments can be compared with each other.

\section{Direct comparisons}

The main characteristics of the included studies are presented in Table 1 and the main results in Table 2.

Study PO25, Mouridsen [31] compared tamoxifen with letrozole. OS indicated no significant difference between groups $(\mathrm{HR}=0.96$ (95\% CI: $0.84,1.09)$. Median TTP was prolonged by $57 \%$, from 6.0 months for tamoxifen to 9.4 months for letrozole (hazard ratio, $0.72 ; P<0.0001$ ). Objective response rate was significantly higher for the randomised letrozole arm, $32 \%$, compared with $21 \%$ for
Fig. 1 Searches for relevant studies (January 2009)

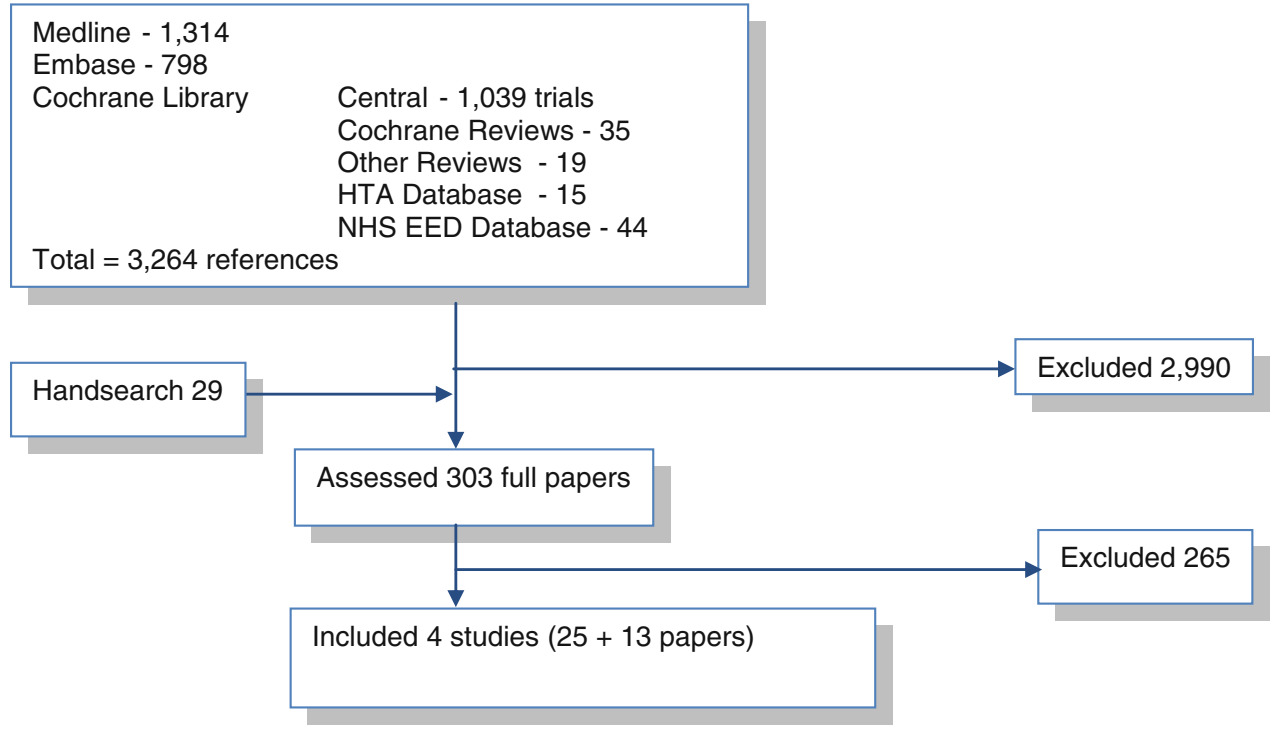


Fig. 2 Network of available comparisons

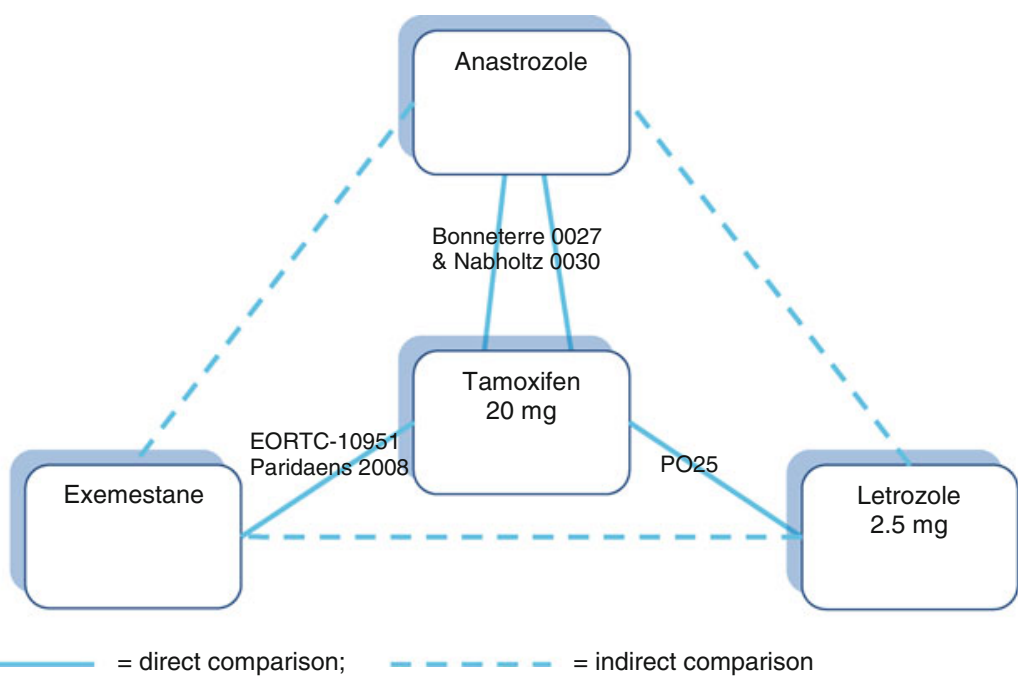

the randomised tamoxifen arm (OR, 1.78; $P=0.0002)$. Quality-adjusted survival was calculated using Q-TWiST (quality-adjusted time without symptoms or toxicity). Survival curves were partitioned into three health states: toxicity (TOX), disease progression (PROG) and periods without toxicity or disease progression (TWiST). There was no significant difference in mean duration of serious adverse events prior to progression between the letrozole and tamoxifen groups (2.2 and 2 months, respectively). For TWiST, the mean duration for letrozole was 11.5 months, versus 8.5 months for tamoxifen $(P<0.001)$. The mean duration of PROG was 11.5 months for letrozole and 12.7 months for tamoxifen $(P=0.047)$. Using utility weights of 0.5 for TOX and PROG resulted in a 2.5-month difference in quality-adjusted survival favouring letrozole $(P<0.0001)$. The incidence of AE's occurring during first-line treatment was similar for letrozole and tamoxifen.

Two studies were found comparing tamoxifen with anastrozole. The North American Trial [29] and the Tamoxifen or Arimidex Randomised Group Efficacy and Tolerability (TARGET) Trial [30]. The trials were prospectively designed to allow for combined data analyses. OS showed no significant differences between groups with $\mathrm{HR}=1.02$ (95\% CI: 0.81, NR) for tamoxifen versus anastrozole in the North American Trial and HR $=0.94$ (95\% CI: 0.79, NR) in the TARGET Trial. In the combined population, $29.0 \%$ of patients in the anastrozole group and $27.1 \%$ in the tamoxifen group achieved an objective response (CR or PR). The difference between groups was not statistically significant $(\mathrm{RR}=0.94$ (95\% CI: 0.78 , 1.15)). In the North American Trial, median time to progression was longer for patients treated with anastrozole compared with tamoxifen (11.1 months for anastrozole and 5.6 months for tamoxifen). In the TARGET Trial there was no significant difference between groups ( 8.3 months for anastrozole and 8.2 months for tamoxifen). Time to progression significantly favoured anastrozole compared to tamoxifen in the North American Trial (HR $=1.42$ (95\% CI: $1.15, \mathrm{NR})$ ); while there was no significant difference between groups in the TARGET Trial (HR $=1.01(95 \%$ CI: $0.87, \mathrm{NR})$ ). In the combined analysis there was no significant difference between groups.

Most adverse events showed no significant differences between groups. Significantly, more patients in the tamoxifen treatment arm experienced thromoboembolic events compared with those receiving anastrozole. The reasons for the apparent discrepancies in efficacy between the two trials were investigated [18]. The authors concluded that the most likely reason lies in the proportion of patients with tumours known to be hormone receptorpositive, which differed markedly between the North American Trial (approximately $90 \%$ of patients) and the TARGET Trial (approximately $45 \%$ of patients).

The comparison of exemestane and tamoxifen showed no differences in OS [45]. The HR for OS was HR $=1.13$ (95\% CI, 0.85-1.50) after 49 months follow-up. A total of 319 events (progression or death) were observed: $161(85 \%)$ in the tamoxifen arm and $158(87 \%)$ in the exemestane arm. The associated HR was 0.84 (95\% CI, 0.67-1.05) in favour of exemestane. The objective response rate (complete plus partial response) was $46 \%$ for exemestane and $31 \%$ for tamoxifen. Consistent with the higher response rate in favour of exemestane (OR $=1.85 ; 95 \%$ CI: 1.21 to 2.82 ), there were fewer patients with disease progression at 29month follow-up with exemestane [33 patients (18.1\%)] than with tamoxifen [54 patients (28.6\%)]. Both treatments were generally well tolerated, and no treatment related deaths were reported. In total, 61 grade 3/4 non-haematologic AEs were observed with tamoxifen versus 41 with exemestane, and 21 grade $3 / 4$ events related to laboratory testing (haematology or chemistry) were recorded with tamoxifen versus 30 with exemestane. 
Table 1 Main characteristics of included trials

\begin{tabular}{|c|c|c|c|c|}
\hline & Bonneterre [30] & Nabholtz [29] & Paridaens [45] & $\mathrm{PO} 25[31]$ \\
\hline Comparison & $\begin{array}{l}\text { Anastrozole ( } 1 \mathrm{mg} / \text { day }) \text { vs } \\
\text { tamoxifen ( } 20 \mathrm{mg} / \text { day })\end{array}$ & $\begin{array}{l}\text { Anastrozole ( } 1 \mathrm{mg} / \text { day) vs } \\
\text { tamoxifen ( } 20 \mathrm{mg} / \text { day })\end{array}$ & $\begin{array}{l}\text { Exemestane }(25 \mathrm{mg} / \text { day }) \mathrm{vs} \\
\text { tamoxifen }(20 \mathrm{mg} / \text { day })\end{array}$ & $\begin{array}{l}\text { Letrozole } 2.5 \mathrm{mg} \text { vs tamoxifen } \\
20 \mathrm{mg} \text { using a double- } \\
\text { dummy technique with } \\
\text { matching placebo tablets }\end{array}$ \\
\hline Design & $\begin{array}{l}\text { Multinational, multicentre, } \\
\text { double-blind RCT }\end{array}$ & $\begin{array}{l}\text { Multinational, multicentre, } \\
\text { double-blind RCT }\end{array}$ & $\begin{array}{l}\text { Multinational, multicentre, } \\
\text { open-label RCT }\end{array}$ & $\begin{array}{l}\text { Multinational, multicentre, } \\
\text { double-blind, double- } \\
\text { dummy, phase III RCT }\end{array}$ \\
\hline$N$ & 668 & 353 & 382 & 906 \\
\hline $\begin{array}{l}\text { Inclusion } \\
\text { criteria }\end{array}$ & $\begin{array}{l}\text { All patients were required to } \\
\text { be postmenopausal and to } \\
\text { have a diagnosis of locally } \\
\text { advanced or metastatic breast } \\
\text { cancer. Patients had to be } \\
\text { suitable for endocrine } \\
\text { therapy as first-line } \\
\text { treatment; prior adjuvant } \\
\text { chemotherapy or endocrine } \\
\text { therapy for early breast } \\
\text { cancer was permissible, but } \\
\text { they were not permitted to } \\
\text { have received tamoxifen } \\
\text { within } 12 \text { months before } \\
\text { entry onto the trial. In } \\
\text { addition, only patients with } \\
\text { HR+ (ER+ and/or PgR+) } \\
\text { tumours or tumours of } \\
\text { unknown hormone receptor } \\
\text { status could be included in } \\
\text { the study }\end{array}$ & $\begin{array}{l}\text { All patients were required to } \\
\text { be postmenopausal, have a } \\
\text { diagnosis of locally } \\
\text { advanced or metastatic breast } \\
\text { cancer, and be suitable to } \\
\text { receive endocrine therapy as } \\
\text { first-line treatment for } \\
\text { advanced disease. Prior } \\
\text { adjuvant chemotherapy or } \\
\text { hormonal therapy for early } \\
\text { breast cancer was permitted, } \\
\text { provided that no patients had } \\
\text { received tamoxifen within } \\
\text { 12 months before entry onto } \\
\text { the trial. Patients were } \\
\text { required to have tumours that } \\
\text { were ER+ and/or PgR+ or } \\
\text { were of unknown receptor } \\
\text { status }\end{array}$ & $\begin{array}{l}\text { Post-menopausal patients with } \\
\text { measurable hormone- } \\
\text { sensitive metastatic or } \\
\text { locally advanced breast } \\
\text { cancer were included. Prior } \\
\text { adjuvant chemotherapy and/ } \\
\text { or tamoxifen were allowed. } \\
\text { One previous chemotherapy } \\
\text { regimen and no prior } \\
\text { hormone therapy for } \\
\text { advanced disease were } \\
\text { permitted }\end{array}$ & $\begin{array}{l}\text { Post-menopausal women with } \\
\text { histologically or } \\
\text { cytologically confirmed } \\
\text { breast cancer and with } \\
\text { locally advanced or loco } \\
\text { regionally recurrent disease } \\
\text { not amenable to treatment by } \\
\text { surgery or radiotherapy or } \\
\text { with metastatic disease. } \\
\text { Patients were required to } \\
\text { have tumours with ER+ and/ } \\
\text { or PgR+ status or with both } \\
\text { receptors unknown. Patients } \\
\text { previously treated with } 1 \\
\text { regimen of chemo-therapy } \\
\text { for advanced disease were } \\
\text { allowed in the study } \\
\text { provided that they had } \\
\text { objective evidence of } \\
\text { progression within } 3 \text { months } \\
\text { before study enrolment }\end{array}$ \\
\hline $\begin{array}{l}\text { Median age } \\
\text { (range) }\end{array}$ & 67 (34-92) years & $67(30-92)$ years & $63(37-87)$ years & $64(31-96)$ years \\
\hline $\begin{array}{l}\text { Performance } \\
\text { status }(\% 0 / \\
1 / 2)\end{array}$ & 0-2: 100\% (WHO) & 0-2: 100\% (WHO) & $44 / 44 / 12 \%$ (WHO) & $\begin{array}{c}90-100: 57 \% ; 70-80: 35 \% \\
\text { 50-60: } 8 \% \text { (Karnofsky) }\end{array}$ \\
\hline $\begin{array}{l}\% \text { HR } \\
\text { unknown }\end{array}$ & $21 \%$ & $11 \%$ & $7 \%$ & $44 \%$ \\
\hline$\%$ HER $2+$ & Not reported & Not reported & Not reported & Not reported \\
\hline $\begin{array}{l}\text { Bone } \\
\text { metastases }\end{array}$ & $47 \%$ & $59 \%$ & $35 \%$ & $30 \%$ \\
\hline $\begin{array}{l}\text { Cross-over } \\
\text { allowed }\end{array}$ & No & No & No & $\begin{array}{l}\text { Yes }(52 \% \text { crossed over to } \mathrm{T} \text {; } \\
50 \% \text { to } \mathrm{L})\end{array}$ \\
\hline $\begin{array}{l}\text { Outcome } \\
\text { Assessor }\end{array}$ & Not reported & Not reported & $\begin{array}{l}\text { Investigator and independent } \\
\text { review committee }\end{array}$ & Not reported \\
\hline $\begin{array}{l}\text { Frequency of } \\
\text { response } \\
\text { assessment }\end{array}$ & Every 4 weeks & $\begin{array}{l}\text { Every } 4 \text { weeks for the first } 12 \\
\text { weeks and then every } 12 \\
\text { weeks after that }\end{array}$ & $\begin{array}{l}\text { Every } 8 \text { weeks up to } 24 \text { weeks } \\
\text { and then every } 12 \text { weeks }\end{array}$ & Every 3 months \\
\hline
\end{tabular}

\section{Indirect comparisons}

In order to make further comparisons between the AIs (letrozole, anastrozole and exemestane), for which direct comparisons were not available, we performed a "networkmeta-analysis" using the methods as described by Puhan et al. [15]. Comparisons were made for objective response rate, OS and progression-free survival (PFS) or time to progression. QOL could not be compared as it was only reported for the PO25 study.

\section{Objective response rate}

In first instance, we focused our analysis on the most relevant available dichotomous outcome: objective response 
Table 2 Main outcomes

\begin{tabular}{|c|c|c|c|c|}
\hline & $\begin{array}{l}\text { Bonneterre [30] } \\
\text { Anastrozole vs } \\
\text { Tamoxifen }\end{array}$ & $\begin{array}{l}\text { Nabholtz [29] } \\
\text { Anastrozole vs } \\
\text { Tamoxifen }\end{array}$ & $\begin{array}{l}\text { Paridaens [45] } \\
\text { Exemestane vs } \\
\text { Tamoxifen }\end{array}$ & $\begin{array}{l}\text { PO25 [31] } \\
\text { Letrozole vs Tamoxifen }\end{array}$ \\
\hline Overall survival (hazard ratio) & $0.94(0.79, \mathrm{NR})$ & $1.02(0.81, \mathrm{NR})$ & $1.13(0.85,1.50)$ & $0.96(0.84,1.09)$ \\
\hline Progression-free survival (HR) & Not reported & Not reported & $0.87(0.70,1.08)$ & Not reported \\
\hline Time to progression (HR) & $1.01(0.87, \mathrm{NR})$ & $1.42(1.15, \mathrm{NR})$ & Not reported & $0.70(0.60,0.82)$ \\
\hline Response rate (risk ratio) & $0.81(0.52,1.25)$ & $0.99(0.80,1.23)$ & $0.68(0.53,0.89)$ & $0.65(0.52,0.82)$ \\
\hline $\begin{array}{l}\text { Quality of Life (mean } \\
\text { difference) }\end{array}$ & Not reported & Not reported & Not reported & $\begin{array}{l}\text { Q-Twist }(\text { all AE, utility weight }=0.5) \\
14.7 \text { versus } 13.2, \text { Difference }=1.5 \\
(P<0.001)\end{array}$ \\
\hline \multicolumn{5}{|l|}{ Adverse events } \\
\hline Death due to $\mathrm{AE}$ & $3.21(0.34,30.58)$ & $1.13(0.38,3.31)$ & & \\
\hline All AE & $1.04(1.00,1.09)$ & $0.93(0.85,1.02)$ & & $1.05(0.80,1.37)$ \\
\hline Serious AE & $0.94(0.64,1.38)$ & $0.86(0.61,1.22)$ & $\begin{array}{l}\mathbf{0 . 6 1}(\mathbf{0 . 3 8}, \mathbf{0 . 9 7})^{\mathrm{a}} \\
1.58(0.87,2.87)^{\mathrm{b}}\end{array}$ & \\
\hline Arthralgia & & & $2.33(1.07,5.11)$ & $1.07(0.75,1.54)$ \\
\hline Bone pain & & & $0.92(0.60,1.41)$ & $1.05(0.77,1.45)$ \\
\hline Constipation & & & $0.65(0.33,1.29)$ & $0.93(0.61,1.43)$ \\
\hline Fatigue & & & $1.01(0.66,1.55)$ & $0.98(0.67,1.45)$ \\
\hline Hot flushes & $1.39(1.03,1.89)$ & $1.04(0.76,1.42)$ & $0.88(0.58,1.35)$ & $1.17(0.83,1.64)$ \\
\hline Nausea & $0.90(0.66,1.22)$ & $0.93(0.63,1.39)$ & $0.84(0.50,1.43)$ & $1.02(0.72,1.44)$ \\
\hline
\end{tabular}

Effects in bold show a significant difference; HR/RR $<1$ in favour of first treatment

$v s$ versus, $N R$ not reported

${ }^{\mathrm{a}}$ Grade 3-4 non-hematologic adverse events, ${ }^{\mathrm{b}}$ Grade 3-4 adverse events (haematology or chemistry)

rate. For each trial arm (2 or 3, depending on the trial), we extracted the number of patients with an objective response (partial or complete response) during follow-up and the number of patients with no objective response during follow-up. Based on $2 \times 2$ tables from each study (or $3 \times 2$ tables, respectively), we created as many data entries with respective coding for treatment and response (yes/no) as there were patients in the respective cell. For example, in the PO25-trial [31] there were 95 patients in the tamoxifen group with an objective response and 359 patients without an objective response, resulting in 95 (objective response $=$ yes) and 359 (objective response $=$ no) data entries for the 454 patients with tamoxifen. For each of these entries we entered the mean age and ER status (percentage confirmed ER-positive as opposed to ER unknown) as covariates. For a detailed description of creating such a data set, see Puhan et al. [15].

We performed a logistic regression arm-level analysis with objective response as dependent and the different treatment options as independent variables. We started with tamoxifen $(20 \mathrm{mg})$ treatment as the reference group followed by identical analyses where letrozole, anastrozole and exemestane, respectively, served as reference group to which the other treatments were compared. To preserve randomisation within each trial, we included a dummy variable for each of the studies. This dummy variable also adjusted for differences in risk profiles and study setup between trials. Second, we intended stratified analyses to assess whether covariates influenced the (relative) treatment effects. However, due to insufficient data within our network these analyses were not possible. All analyses were conducted using STATA (STATA ${ }^{\mathrm{TM}}$ for Windows, version 10, Stata Corp; College Station, TX).

The results of our network analysis, focusing on the main comparisons while using data from all comparisons (see Fig. 2) are shown in Table 3.

Exemestane appeared to be the best treatment in terms of objective response rates, followed by letrozole and anastrazole. Exemestane and letrozole appeared to be significantly better than anastrozole and tamoxifen. Figure 3 shows all treatments comparison with tamoxifen.

\section{Overall survival}

We would have preferred to use outcomes such as OS, PFS or TTP in our "network-meta-analysis". However, to use these continuous outcomes we need separate results for each treatment arm with the corresponding estimate for the variance. Since most trials did not provide this level of 
Table 3 Results of network analysis using objective response rate (dichotomous: $1=$ partial or complete response; $0=$ no response) as outcome

\begin{tabular}{llll}
\hline Treatment & \multicolumn{2}{l}{ Comparator } & \\
\cline { 2 - 4 } & Tamoxifen & Letrozole & Anastrozole \\
\hline Letrozole & $\mathbf{0 . 5 6}^{\mathrm{a}}(\mathbf{0 . 4 2 ,} \mathbf{0 . 7 6})$ & & \\
Anastrozole & $0.95^{\mathrm{a}}(0.72,1.24)$ & $\mathbf{1 . 6 8}(\mathbf{1 . 1 2}, \mathbf{2 . 5 2})$ & \\
Exemestane & $\mathbf{0 . 5 4}^{\mathrm{a}}(\mathbf{0 . 3 5}, \mathbf{0 . 8 3})$ & $0.96(0.57,1.62)$ & $\mathbf{0 . 5 7}(\mathbf{0 . 3 5}, \mathbf{0 . 9 5})$
\end{tabular}

Values in bold represent significant difference in terms of objective response rate; odds ratio $<1$ indicates greater likelihood of better response on treatment versus comparator

${ }^{a}$ Direct comparisons

detail we decided to do a series of indirect comparisons (using Bucher's method) [14] including the main treatments (exemestane, letrozole, anastrozole and tamoxifen; see Fig. 2) to produce an overview of the network, this time in terms of OS and PFS/TTP.

The results of these indirect comparisons for OS are presented in Table 4. For OS, there appears to be no significant differences between the three AIs.

The results in comparison with tamoxifen are presented in Fig. 4. There were no statistically significant differences between treatments.

\section{Progression-free survival/time-to-progression}

For OS, the definitions of the outcome were similar between trials. However, that is not the case for PFS and TTP. PFS (usually defined as progression and all death) and TTP (usually defined as progression and death due to progression only) are not equivalent in definition and although on some occasions there may be little difference, if there are a large number of deaths due to factors other than progression then the effects can differ significantly.

In three out of four comparisons TTP was reported only [29-31]; one trial reported PFS only [45].

Where possible we have used TTP as this was the outcome most often reported. When TTP was not reported, we have used PFS assuming this was similar to TTP. For one trial [45], we have no information about whether this
Table 4 Outcome overall survival (OS) as defined in the study (treatment versus comparator)

\begin{tabular}{llll}
\hline Treatment & Comparator & & \\
\cline { 2 - 4 } & Tamoxifen & Letrozole & Anastrozole \\
\hline Letrozole & $0.96^{\mathrm{a}}(0.84,1.09)$ & & \\
Anastrozole & $1.03^{\mathrm{a}}(0.88,1.22)$ & $1.08(0.87,1.32)$ & \\
Exemestane & $1.13^{\mathrm{a}}(0.85,1.50)$ & $1.18(0.86,1.61)$ & $1.10(0.79,1.52)$
\end{tabular}

Values in bold represent significant difference in terms of overall survival; hazard ratio $<1$ indicates greater likelihood of better response on treatment versus comparator

${ }^{\text {a }}$ Head-to-head comparison

assumption is reasonable or not. Therefore, the results of this analysis need to be interpreted with extreme caution.

The results of these indirect comparisons for PFS and TTP are presented in Table 5. There appear to be no significant differences between the three AIs in terms of PFS and TTP.

The results in comparison with tamoxifen are presented in Fig. 5. Letrozole was significantly superior to tamoxifen.

\section{Discussion}

A systematic review was undertaken of three first-line treatments (letrozole, anastrozole and exemestane) for hormone sensitive advanced or MBC in post-menopausal women.

Four studies (25 papers) met the inclusion criteria. From the available evidence, it was possible to directly compare the three AIs with tamoxifen. In addition, by using a network meta-analysis it was possible to compare the three AIs with each other. Head-to-head comparisons of AIs with each other, have been or are currently being performed in the second-line, the adjuvant and neoadjuvant settings, but have not been performed in the first-line metastatic setting. Therefore, we found no completed or ongoing studies comparing AIs with each other in the first-line metastatic setting.

Based on direct evidence, letrozole seemed to be significantly better than tamoxifen in terms of TTP, objective response rate and quality-adjusted time without symptoms
Fig. 3 Objective response rates in comparison with tamoxifen

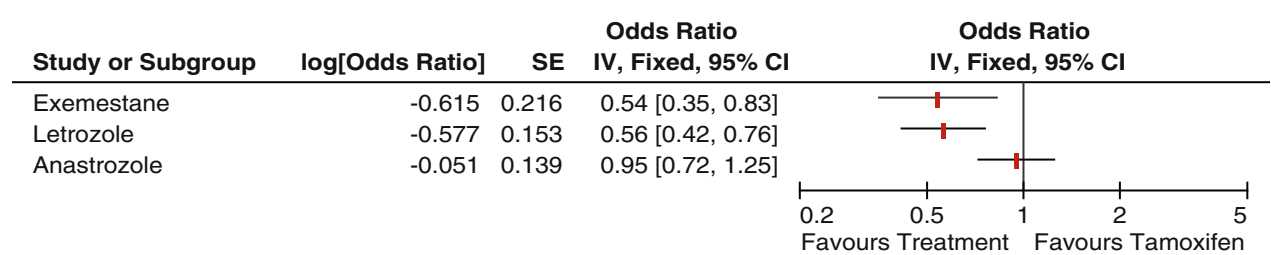


Fig. 4 Overall survival in comparison with tamoxifen

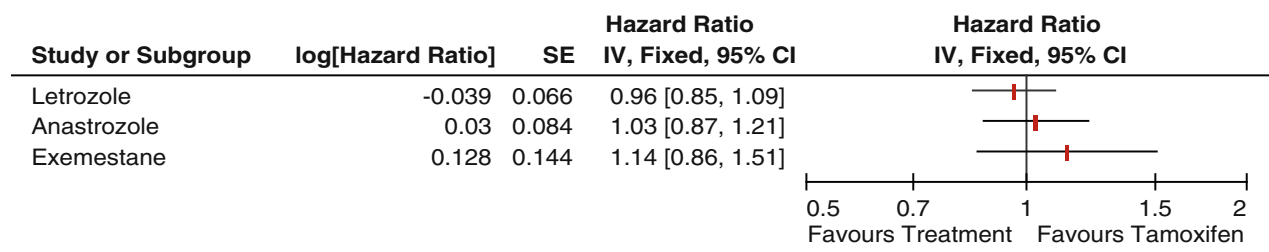

Comparison with other reviews

Table 5 Outcome Progression-Free Survival (PFS) or Time-to-Progression (TTP) (treatment versus comparator)

\begin{tabular}{llll}
\hline Treatment & Comparator & & \\
\cline { 2 - 4 } & Tamoxifen & Letrozole & Anastrozole \\
\hline Letrozole & $\mathbf{0 . 7 0}^{\mathrm{a}}(\mathbf{0 . 6 0}, \mathbf{0 . 8 2})$ & & \\
Anastrozole & $0.85^{\mathrm{a}}(0.71,1.01)$ & $1.22(0.96,1.54)$ & \\
Exemestane & $0.87^{\mathrm{a}}(0.70,1.08)$ & $1.24(0.95,1.62)$ & $1.02(0.79,1.35$
\end{tabular}

Values in bold represent significant difference in terms of overall survival; hazard ratio $<1$ indicates greater likelihood of better response on treatment versus comparator

${ }^{\text {a }}$ Head-to-head comparison

or toxicity. Exemestane seemed significantly superior to tamoxifen in terms of objective response rate. Anastrozole seemed significantly superior to tamoxifen in terms of TTP in one trial, but not in the other. For OS and objective response rate no significant differences were found between anastrozole and tamoxifen.

In terms of adverse events, no significant differences were found between letrozole and tamoxifen. Tamoxifen was associated with significantly more serious adverse events in comparison with exemestane; while exemestane was associated with significantly more arthralgia in comparison with tamoxifen. Anastrozole was associated with significantly more total adverse events and hot flushes in comparison with tamoxifen in one trial; however, the other trial showed no significant differences in adverse events between anastrozole and tamoxifen.

The indirect comparison of AIs with each other in women with post-menopausal, hormone sensitive advanced or MBC appeared to show that the three AIs do not significantly differ from each other in terms of OS and PFS or time to progression. Only for objective response rate, letrozole and exemestane showed a significant advantage over anastrozole.
Altundag et al. [54] examined the use of aromatase inhibitors (AIs) in post-menopausal patients with hormone receptor-positive breast cancer. They conclude that current data [29-31, 45] indicate that AIs are equivalent or superior to tamoxifen as first-line therapy for MBC. This is consistent with our findings.

Berry et al. [55] reviewed the results of recent randomised, controlled clinical trials of the AIs in the settings of neoadjuvant, adjuvant and advanced/MBC. They found that in three Phase III studies (one letrozole versus tamoxifen [31], two anastrozole versus tamoxifen [29, 30]), both anastrozole and letrozole were more efficacious than tamoxifen in the first-line setting, and some patients receiving letrozole had better overall response rates compared with those receiving anastrozole in the second-line setting ( 19.1 vs. $12.3 \%$, respectively; $P=0.013$ ). Again, this is consistent with our findings.

Ferretti et al. [56] evaluated the effectiveness (overall response rate (ORR), clinical benefit (CB), TTP, OS) and toxicity of AIs, compared with tamoxifen as first-line endocrine therapy in post-menopausal MBC women. Based on six phase III prospective randomised trials [29-31, 53, $57,58]$, including 2,787 women, they found a significant advantage in ORR $(P=0.042)$, TTP $(P=0.007)$ and CB $(P=0.001)$ in favour of AI over tamoxifen using a fixedeffect model. These results were not significant when using the random effects model, owing to significant heterogeneity. No difference was registered for OS $(P=0.743)$ with no significant heterogeneity. Regarding toxicity, tamoxifen was associated with a increase in thromboembolic events $(P=0.005)$ and vaginal bleeding $(P=0.001)$ compared with AI. Our findings also showed no significant differences for OS. However, our findings showed a significant difference between letrozole and tamoxifen in terms of ORR and TTP, and between exemestane and
Fig. 5 Progression-free survival/time-to-progression in comparison with tamoxifen

\begin{tabular}{|c|c|c|c|c|c|}
\hline Study or Subgroup & log[Hazard Ratio] & SE & $\begin{array}{l}\text { Hazard Ratio } \\
\text { IV, Fixed, } 95 \% \text { CI }\end{array}$ & $\begin{array}{r}\text { Haza } \\
\text { IV, Fix }\end{array}$ & $\begin{array}{l}\text { rd Ratio } \\
\text { ed, } 95 \% \mathrm{Cl}\end{array}$ \\
\hline Letrozole & -0.358 & 0.08 & $0.70[0.60,0.82]$ & -1 & \\
\hline Anastrozole & -0.166 & 0.09 & $0.85[0.71,1.01]$ & $\longrightarrow$ & \\
\hline Exemestane & -0.14 & 0.11 & $0.87[0.70,1.08]$ & $\longrightarrow$ & \\
\hline
\end{tabular}


tamoxifen in terms of ORR. Ferreti et al. included three of the four studies included in this review (Nab,Bon,Mou), the fourth study (Par) was mentioned, but since data from a conference abstract only were available, it was not included in their main analyses. In addition, Ferreti et al. included three studies that were excluded in our review: Milla-Santos et al. compared anastrazole with $40 \mathrm{mg}$ tamoxifen, which we did not regard as comparable with $20 \mathrm{mg}$ in the other trials; Perez-Carion et al. compared formestane with $30 \mathrm{mg}$ tamoxifen and Thürlimann et al. compared fadrozole with tamoxifen.

In a Cochrane Systematic Review, Gibson et al. compared AIs to other endocrine therapy in the treatment of advanced breast cancer in post-menopausal women [5]. In 10 of the 30 included studies (randomising 3,635 women) any AI was used as first-line treatment versus any other comparator, which was tamoxifen in all of them. Gibson et al. found an advantage of treatment with AIs in terms of PFS $(\mathrm{HR}=0.78(95 \%$ CI 0.70 to 0.86$))$ and clinical benefit $(\mathrm{OR}=0.70$; $(95 \% \mathrm{CI} 0.51$ to 0.97$)$ ) but not OS or objective response. There was considerable heterogeneity across studies when considering clinical benefit $(P=0.001)$. Gibson et al. also stated that AIs have a different toxicity profile to other endocrine therapies. For all AIs combined, they had similar levels of hot flushes (especially when compared to tamoxifen) and arthralgia, increased risks of nausea, diarrhoea and vomiting, but a decreased risk of vaginal bleeding and thromboembolic events compared with other endocrine therapies. Gibson included all four studies included in our review (Bon,Nab,Mou,Par) (treating the North American and TARGET trials as one study) and the study by Milla-Santos et al. comparing anastrazole with $40 \mathrm{mg}$ tamoxifen (see above). In addition, 6 studies were included comparing aminoglutethimide [Alonso,Powles,Rose], fomestane [Perez] and fadrozole[falk, Thurl] with tamoxifen. Gibson et al. also presented a comparison of AIs versus any other AI including four studies [Gersh,Rose,Tom,Klee], but none of these studies were in first-line treatment. A comparison of anastrozole, exemestane and letrozole with each other as first-line treatment of advanced breast cancer in postmenopausal women, which is only possible using indirect comparisons, was not reported by Gibson et al.

Strength, limitations and uncertainties

Although this review sought wherever possible to reduce the risk of bias during the review processes and analysis, the findings of the review may still be subject to certain limitations and uncertainties beyond our control.

In most cases, the studies adequately reported their methods but some information particularly regarding blinding was missing from some of the studies. The included studies may well have fulfilled all of the quality criteria, but due to poor reporting by the study authors or word limitations imposed by journal publications, key information was missing and so criteria were assessed as unclear.

On a further note, one study used an open design which may have introduced bias through patients and clinicians having knowledge of the study treatment being received [45]. It was also difficult in a number of cases to determine whether study outcomes were measured by a blinded assessor. Only one of the four included studies clearly stated that the final outcome data were assessed or verified by an independent or blinded assessor [45]. The remaining studies failed to report this information. Assessor blinding or independent verification of outcomes is particularly important where subjective outcomes such as disease progression and response are being assessed. Prior knowledge of the treatment being received may lead intentionally or unintentionally to the biased assessment of outcomes in favour of the new treatment being investigated.

None of the studies reported concomitant use of bisphosphonates for the active management of metastatic bone disease. These studies were, however, conducted at a time when such treatment was not part of routine treatment protocols and is therefore unlikely to have had a significant impact.

OS is the primary outcome of interest to both clinicians and patients. However, in one study patients were crossed over to the alternative study treatment upon disease progression as a protocol procedure [31]. The presence of crossover is likely to influence the OS observed in these studies of endocrine responsive disease. Along with the drive to license and approve drugs for the treatment of patients with breast and other forms of cancer, there is now a move to use PFS as a surrogate outcome for OS. PFS in addition to OS was also assessed. However, the use of this outcome is also not without potential bias. There is likely to be a lag period between the occurrence of progression and its identification within the trial due to the frequency of outcome assessment. Therefore, the follow-up time point at which progression is first evident is used as a proxy for the true progression time. In all four included trials outcome assessments were carried out every 3 months, so if progression occurred shortly after an assessment there may be a lag period of 2 months or so before it is detected at the following assessment 3 months later unless accompanied by symptoms prompting earlier investigation and identification of progression. This over-estimation can erroneously lead to a result being described as clinically significant when in fact a longer PFS may just be a consequence of the length of the surveillance interval [59]. One possible way to 
compensate for this lag is to record progression as occurring at the assessment time point prior to the time point it was actually identified. However, this type of information was not readily available in the included trials. The fact that all trials carried out routine assessments every 3 months suggests that their outcomes are comparable in this respect; it is not always an accurate measure of the true period of PFS [60].

Only one study [45] reported PFS, however, three [2931] reported TTP. In order to allow the assessment of this important outcome both PFS and TTP data were included in the analysis. However, these two outcomes are not necessarily equivalent depending on the outcome definitions used and the individual circumstances within the trial. PFS is traditionally defined as the time from randomisation (or registration, in non-randomised trials) to objective tumour progression, or death from any cause, whichever first [61]. However, because PFS includes deaths as part of the endpoint, it may correlate better to OS. In TTP, informative censoring occurs as deaths are censored (either at the time of death or at an earlier visit) and deaths may be due to tumour progression. PFS assumes patient deaths are related to tumour progression or underlying disease. However, if most deaths are due to causes unrelated to cancer, TTP can be a more meaningful endpoint [62]. In this review there were some differences in the definitions of PFS and TTP. By using a mixture of PFS and TTP data, it may be possible that we are not comparing 'like with like'. This may also be the case depending on how the outcome is assessed and whether assessment is based on a decision by the investigator, an independent observer or review board or a mixture of the two types of assessment. If investigators are not blinded to the treatment allocation, their assessment may be subject to bias, whereas data from an external, independent, blinded assessor or group of assessors where the potential for such bias is likely to be reduced. In three of the included studies the authors failed to report the type of assessment used, so this must be borne in mind when interpreting the results. This problem also applies to other outcomes such as ORR.

Institutions such as the National Institute for Health \& Clinical Excellence (NICE) have placed increasing importance on Quality of Life (QoL) as a clinically important outcome in cancer trials. In this review QoL data was found in one out of four included studies [31]. Mouridsen et al. [31] used Q-TWiST analyses to calculate quality-adjusted survival in the PO25 trial.

Missing study information and data not only affected the analysis and interpretation of included studies, but may also have influenced the inclusion of studies in the review. In order to minimise the risk of publication and language bias, search methods strived to identify all studies regardless of publication status or language. However, despite obtaining full publications or abstracts there was sometimes insufficient data to determine whether the study met the inclusion criteria. This was particularly the case when assessing the hormone receptor status of patients, or their treatment status (i.e. what treatments if any they had previously received for advanced/MBC). Regarding previous treatments, some trials stated they were first-line but still included patients who had received previous therapies for advanced disease. The decision was made to include such studies if they stated they were designed to assess first-line treatment and only included 10\% (or less) of patients previously treated for advanced disease.

This review included studies in which patients were hormone receptor-positive, i.e. patients with ER-positive or unknown and/or PgR-positive or unknown breast cancer. However, there were large differences in the number of ER unknown patients across studies. The number of ER-positive patients ranged from 45 to $93 \%$, with one study in which ER status was unknown in more than $50 \%$ of patients [30]. In the TARGET [30] and North American [29] trials, there was a major difference between the two individual trials with respect to the proportion of patients with confirmed receptor positive tumours. A retrospective analysis of subgroups of patients defined by tumour receptor status (those with $\mathrm{ER}+$ and/or $\mathrm{PgR}+$ tumours compared with those with tumours of unknown receptor status) in the combined study population indicated that anastrozole was significantly more beneficial compared with tamoxifen in terms of extending the TTP in those patients whose tumours were $\mathrm{ER}+$ and/or $\mathrm{PgR}+$ (median TTP was 10.7 and 6.4 months for anastrozole and tamoxifen, respectively, two-sided $P=0.022$ ). The authors stated that "this analysis indicated that, for the overall combined results, the benefits of anastrozole compared with tamoxifen may have been diluted by the high proportion of patients of unknown receptor status in the combined study population" [19]. In addition to the probable contamination of these trials by hormone receptor negative patients within the unknown cohorts the hormone receptor assays were conducted in multiple laboratories with no central confirmation in a reference laboratory which possibly adds further to the difficulties in determining the degree of heterogeneity across trial populations. Heterogeneity between the included studies needs to be borne in mind when interpreting the findings from the network meta-analysis, as the validity of indirect comparisons is dependent on the basic assumptions of homogeneity, similarity and consistency between studies as outlined in Song et al. [63].

It was intended to include the effect of unknown ER status as a variable in a meta-regression analysis but this was not possible because of insufficient data in the 
network. This also applies to other potential confounding factors such as bone metastases and performance status. Although performance status is unlikely to be a problem, as most studies included patients with a similar status.

Summary of main effects

Based on direct evidence, letrozole seemed to be significantly better than tamoxifen in terms of TTP, objective response rate and quality-adjusted time without symptoms or toxicity. Exemestane seemed significantly superior to tamoxifen in terms of objective response rate. Anastrozole seemed significantly superior to tamoxifen in terms of TTP in one trial, but not in the other.

In terms of adverse events, no significant differences were found between letrozole and tamoxifen. Tamoxifen was associated with significantly more serious adverse events in comparison with exemestane; while exemestane was associated with significantly more arthralgia in comparison with tamoxifen. Anastrozole was associated with significantly more total adverse events and hot flushes in comparison with tamoxifen in one trial; however, the other trial showed no significant differences in adverse events between anastrozole and tamoxifen.

The indirect comparison of AIs with each other in women with post-menopausal, hormone sensitive advanced or MBC appeared to show that letrozole and exemestane were better in terms of objective response rate than anastrozole; while the more clinically relevant outcomes of OS and PFS showed no significant differences between AIs.

Though results of this study need to be interpreted with caution since they are based on indirect comparisons, they provide no evidence that any of the AIs is significantly better that the others in terms of the key endpoints of OS and PFS. Therefore, a possible AI class effect should be considered. Furthermore, the National Comprehensive Cancer Network (NCCN) and the European Society for Medical Oncology (ESMO) treatment guidelines suggest their equivalence by stating that any one of the third generation AIs may be used for the front-line treatment of hormone receptor-positive $\mathrm{MBC}$ in postmenopausal patients without visceral crisis [64, 65]. The National Institute for Health and Clinical Excellence recently (June 2009) issued guidance for hormonal therapies for the adjuvant treatment of early oestrogen receptor-positive breast cancer, noting "there is convincing evidence that all three AIs, within their respective licensed indications, provide clinical benefit over tamoxifen in primary adjuvant or unplanned switch treatment, and over placebo in extended adjuvant treatment" [66]. The Committee con- sidered the differences between the clinical trials and agreed that there is insufficient evidence to conclude that any one AI (used within the licensed indications) or treatment strategy is more clinically effective than another. Our results confirm these conclusions.

\section{Conclusion}

OS and PFS showed no significant differences between AIs and hence based on these results a class effect for all AIs is possible. However, these results are based on indirect comparisons and a network analysis for which the basic assumptions of homogeneity, similarity and consistency were not fulfilled. Therefore, despite the fact that these are the best available data, the results need to be interpreted with appropriate caution. Head-to-head comparisons between letrozole, anastrozole and exemestane in the firstline MBC setting would be required to robustly demonstrate any clinically important differences in efficacy between these agents. However, a greater priority at present may be to focus on the integration of established endocrine agents in combination with the current generation of biological therapies. These trials should be conducted where possible with appropriately selected biologically relevant subgroups or at the very least should incorporate prospectively powered hypotheses to test for the presence of clinically important differences in outcome within pre-specified clinicopathological subgroups. In this context it is a matter of speculation as to whether the choice of different AIs as endocrine partner to new biological agents would have a critical bearing on any findings and it may be helpful to attempt to determine the most appropriate candidate endocrine partner through preclinical models or neoadjuvant window studies.

Acknowledgements The project was funded by GlaxoSmithKline. Konstantinos Lykopoulos and Mayur Amonkar both work for GlaxoSmithKline. Daniel Rea received honoraria from Pfizer, Novartis and Astra Zeneca and he received research funding to his institution from Pfizer, Novartis and Astra Zeneca, and provided consultancy to Novartis, Pfizer and Astra Zeneca.

Conflict of interest statement Rob Riemsma, Carol Forbes, Fons Kessels, and Jos Kleijnen have no other conflicts of interest. Furthermore, RR, CF, FK and JK had ultimate editorial control of the manuscript.

\section{Appendix 1: Search strategies}

See Table 6. 
Table 6 Ovid MEDLINE(R)

In-process and other nonindexed citations and Ovid MEDLINE(R) 1950—Present (21-01-2009)

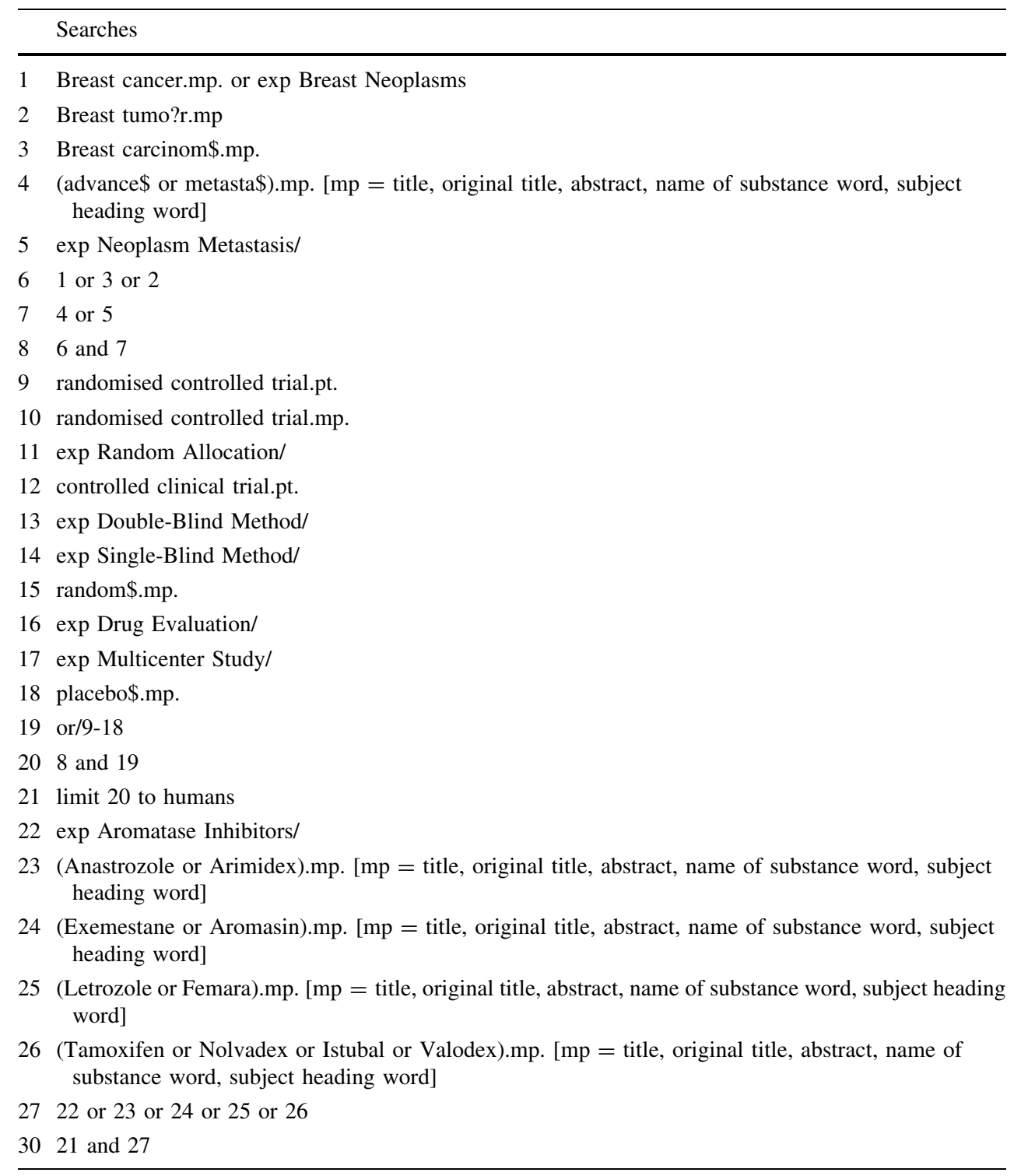

\section{Appendix 2}

See Table 7.

Table 7 Quality assessment

\begin{tabular}{|c|c|c|c|c|}
\hline Domain & $\begin{array}{l}\text { Bonneterre } \\
2000 \\
{[30]}\end{array}$ & $\begin{array}{l}\text { Nabholtz } \\
2000 \\
{[29]}\end{array}$ & $\begin{array}{l}\text { Paridaens } \\
2008 \\
{[45]}\end{array}$ & $\begin{array}{l}\mathrm{PO} 25 \\
{[31]}\end{array}$ \\
\hline Was the allocation sequence adequately generated? & Yes & Yes & Unclear & Yes \\
\hline Was allocation adequately concealed? & Yes & Yes & Yes & Unclear \\
\hline Was knowledge of the allocated intervention adequately prevented during the study? & Unclear & Unclear & No & Yes \\
\hline Were incomplete outcome data adequately addressed? & Yes & Yes & Yes & Yes \\
\hline Are reports of the study free of suggestion of selective outcome reporting? & Yes & Yes & Yes & Yes \\
\hline $\begin{array}{l}\text { Was the study apparently free of other problems that could put it at a high risk } \\
\text { of bias? }\end{array}$ & Yes & Yes & Yes & Yes \\
\hline
\end{tabular}




\section{References}

1. Cancer Research UK (2009) CancerStats key facts on breast cancer. http://info.cancerresearchuk.org/cancerstats/types/breast/ incidence/?a=5441. Accessed 25 Aug 2009

2. Cancer Research UK (2009) UK breast cancer mortality statistics. http://info.cancerresearchuk.org/cancerstats/types/breast/mortality/ $? \mathrm{a}=5441$. Accessed 25 Aug 2009

3. National Institute for Health and Clinical Excellence (2009) Draft scope for the appraisal of lapatinib for the first-line treatment of metastatic hormone sensitive breast cancer (Issue Date April 2009), 25 June 2009

4. Early Breast Cancer Trialists' Collaborative Group (EBCTCG) (2005) Effects of chemotherapy and hormonal therapy for early breast cancer on recurrence and 15-year survival: an overview of the randomised trials. Lancet 365(9472):1687-1717

5. Gibson LJ, Dawson CK, Lawrence DH, Bliss JM(2007) Aromatase inhibitors for treatment of advanced breast cancer in postmenopausal women. Cochrane Database Syst Rev (1):CD003370

6. Howell A, Dowsett M (2004) Endocrinology and hormone therapy in breast cancer: aromatase inhibitors versus antioestrogens. Breast Cancer Res 6(6):269-274

7. Dixon JM, Renshaw L, Young O, Murray J, Macaskill EJ, McHugh M et al (2008) Letrozole suppresses plasma estradiol and estrone sulphate more completely than anastrozole in postmenopausal women with breast cancer. J Clin Oncol 26:1671-1676

8. Geisler J, Haynes B, Anker G (2002) Influence of letrozole and anastrozole on total body aromatization and plasma estrogen levels in postmenopausal breast cancer evaluated in a randomized, cross-over study. J Clin Oncol 20:751-757

9. National Institute for Clinical Excellence (2002) Guidance on the use of trastuzumab for the treatment of advanced breast cancer. Technology Appraisal Guidance no. 34. London, NICE. http:// www.nice.org.uk/nicemedia/live/11445/32313/32313.pdf. March 2002

10. Dawood S, Broglio K, Buzdar AU, Hortobagyi GN, Giordano SH (2010) Prognosis of women with metastatic breast cancer by HER2 status and trastuzumab treatment: an institutional-based review. J Clin Oncol 28(1):92-98

11. Johnston SR, Pegram M, Press M, Pippen J, Pivot X, Gomez HL, et al (2008) Lapatinib combined with letrozole vs. letrozole alone for front line postmenopausal hormone receptor positive (HR+) metastatic breast cancer (MBC): first results from the EGF30008 Trial. In: San Antonio Breast Cancer Symposium, 31st Annual SABCS, 10-14 December 2008

12. Kaufman B (2006) Trastuzumab plus anastrozole prolongs progression-free survival in postmenopausal women with HER2 positive, hormone-dependent metastatic breast cancer (MBC). In: European Society for Medical Oncology (ESMO) Congress, 29 September to 3 October, Istanbul, Turkey

13. Higgins JPT, Green S (eds) (2008) Cochrane handbook for systematic reviews of interventions Version 5.0.1 (updated September 2008). The Cochrane Collaboration, Oxford

14. Bücher HC, Guyatt GH, Griffiths LE, Walter SD (1997) The results of direct and indirect treatment comparisons in metaanalysis of randomized controlled trials. J Clin Epidemiol 50(6):683-691

15. Puhan MA, Bachmann LM, Kleijnen J, Ter Riet G, Kessels AG (2009) Inhaled drugs to reduce exacerbations in patients with chronic obstructive pulmonary disease: a network meta-analysis. BMC Med 14(7):2

16. Nabholtz JM, Bonneterre J, Buzdar AU, Thürlimann BJK, Robertson JFR, Webster A et al (1999) Preliminary results of two multi-center trials comparing the efficacy and tolerability of arimidex (anastrozole) and tamoxifen (TAM) in postmenopausal
(PM) women with advanced breast cancer (ABC). Breast Cancer Res Treat 57(1):31

17. Nabholtz JM, Bonneterre J, Buzdar A, Robertson JFR, Thurlimann B (2003) Anastrozole (Arimidex) versus tamoxifen as firstline therapy for advanced breast cancer in postmenopausal women: survival analysis and updated safety results. Eur J Cancer 39(12):1684-1689

18. Nabholtz JM (2003) Advanced breast cancer updates on anastrozole versus tamoxifen. J Steroid Biochem Mol Biol 86(35):321-325

19. Bonneterre J, Buzdar A, Nabholtz J-M, Robertson JFR, Thürlimann B, Von Euler M et al (2001) Anastrozole is superior to tamoxifen as first-line therapy in hormone receptor positive advanced breast carcinoma: results of two randomized trials designed for combined analysis. Cancer 92(9):2247-2258

20. Bonneterre JM, Nabholtz JM, Buxdar A, Robertson J, Thürlimann B (2002) Anastrozole compared with tamoxifen as first-line therapy for postmenopausal women with advanced breast cancer-survival analyses. Ann Oncol 13:47

21. Buzdar A, Nabholtz JM, Robertson JF, Thürlimann BJK, Bonneterre J, Von Euler M, Steinberg M, Webster A (2000) Anastrozole ('Arimidex') versus tamoxifen as first-line therapy for advanced breast cancer $(\mathrm{ABC})$ in postmenopausal $(\mathrm{PM})$ women: combined analysis from two identically designed multicenter trials. Proc Am Soc Clin Oncol 19:154a (abstr 609D). http://www.asco.org/ASC Ov2/Meetings/Abstracts?\&vmview=abst_detail_view\&confID $=2$ \&abstractID=200259

22. Buzdar A, Bonneterre J, Nabholtz JM, Robertson JFR, Thürlimann B, Von Euler M et al (2000) Anastrazole (AN) versus tamoxifen (TAM) as first-line therapy for advanced breast cancer $(\mathrm{ABC})$ in post-menopausal (PM) women: findings highlight the importance of receptor status assessment prior to treatment initiation. Ann Oncol 11(Suppl-4):25

23. Thürlimann B, Nabholtz JM, Bonneterre J, Buzdar AU, Robertson JFR, Webster A et al (1999) Preliminary results of two comparative multicentre clinical trials comparing the efficacy and tolerability of Arimidex TM (anastrozole) and tamoxifen (TAM) in postmenopausal women with advanced breast cancer (ABC). The Breast 8(4):214

24. Thürlimann BJK, Bonneterre J, Buzdar A, Nabholtz J-M, Robertson FR, Sahmoud T (2001) First line endocrine therapy in postmenopausal patients with advanced breast cancer and visceral metastases: anastrozole (Arimidex) versus tamoxifen. Proc Am Soc Clin Oncol 20 (abstr 1835). http://www.asco.org/ASCOv2/Meetings/Abstracts? \&vmview=abst_detail_view\&confID $=10 \&$ abstractID $=1835$

25. Robertson J, Buzdar A, Nabholtz JM, Thürlimann B, Bonneterre J, Von Euler M (2000) Anastrozole (Arimidex) versus tamoxifen as first-line therapy for advanced breast cancer (ABC) in postmenopausal (PM) women-prospective combined analysis from two international trials. Eur J Cancer 36(Suppl-5):S88

26. Robertson JFR, on behalf of the Arimidex 1st-Line Study Group (2008) Anastrozole (Arimidex) versus tamoxifen as 1st-line therapy for advanced breast cancer (ABC) in post-menopausal (PM) women-combined analysis from two identically designed multicenter trials. Br J Cancer 83:39

27. AstraZeneca P (2001) Randomised, double-blind trials to compare the efficacy and safety of Arimidex (anastrozole $1 \mathrm{mg}$ daily) with tamoxifen (20 mg daily) as first-line therapy for advanced breast cancer in postmenopausal women: safety and survival update 2001 (1033IL/0030 and 1033IL/0027). Trial Report. http://www. astrazenecaclinicaltrials.com/_mshost800325/content/clinicaltrials/ resources/pdf/8609896

28. Vergote I, Thürlimann B (2001) First-line endocrine therapy in postmenopausal patients with advanced breast cancer and visceral metastases: anastrozole versus tamoxifen. Eur J Cancer 37:191 
29. Nabholtz JM, Buzdar A, Pollak M, Harwin W, Burton G, Mangalik A et al (2000) Anastrozole is superior to tamoxifen as firstline therapy for advanced breast cancer in postmenopausal women: results of a North American multicenter randomized trial. Arimidex Study Group. J Clin Oncol 18(22):3758-3767

30. Bonneterre J, Thurlimann B, Robertson JF, Krzakowski M, Mauriac L, Koralewski P et al (2000) Anastrozole versus tamoxifen as first-line therapy for advanced breast cancer in 668 postmenopausal women: results of the Tamoxifen or Arimidex Randomized Group Efficacy and Tolerability study. J Clin Oncol 18(22):3748-3757

31. Mouridsen HT (2007) Letrozole in advanced breast cancer: the PO25 trial. Breast Cancer Res Treat 105(Suppl-1):19-29

32. Irish W, Sherrill B, Cole B, Gard C, Glendenning GA, Mouridsen $\mathrm{H}$ (2005) Quality-adjusted survival in a crossover trial of letrozole versus tamoxifen in postmenopausal women with advanced breast cancer. Ann Oncol 16(9):1458-1462

33. Mouridsen H, Gershanovich M, Sun Y, Perez-Carrion R, Boni C, Monnier A et al (2001) Superior efficacy of letrozole versus tamoxifen as first-line therapy for postmenopausal women with advanced breast cancer: results of a phase III study of the International Letrozole Breast Cancer Group. J Clin Oncol 19(10):2596-2606

34. Mouridsen H, Gershanovich M, Sun Y, Perez-Carrion R, Boni C, Monnier A et al (2003) Phase III study of letrozole versus tamoxifen as first-line therapy of advanced breast cancer in postmenopausal women: analysis of survival and update of efficacy from the international letrozole breast cancer group. J Clin Oncol 21(11):2101-2109

35. Mouridsen H, Chaudri-Ross HA (2004) Efficacy of first-line letrozole versus tamoxifen as a function of age in postmenopausal women with advanced breast cancer. Oncologist 9(5):497-506

36. Mouridsen H, Sun Y, Gershanovich M, Perez-Carrion R, Becquart D, Chaudri-Ross HA et al (2004) Superiority of letrozole to tamoxifen in the first-line treatment of advanced breast cancer: evidence from metastatic subgroups and a test of functional ability. Oncologist 9(5):489-496

37. Lipton A, Ali SM, Leitzel K, Demers L, Harvey HA, ChaudriRoss HA et al (2003) Serum HER-2/neu and response to the aromatase inhibitor letrozole versus tamoxifen. J Clin Oncol 21(10): 1967-1972

38. Lipton A, Leitzel K, Chaudri-Ross HA, Evans DB, Ali SM, Demers L et al (2008) Serum TIMP-1 and response to the aromatase inhibitor letrozole versus tamoxifen in metastatic breast cancer. J Clin Oncol 26(16):2653-2658

39. Smith IE (2003) Letrozole versus tamoxifen in the treatment of advanced breast cancer and as neoadjuvant therapy. J Steroid Biochem Mol Biol 86(3-5):289-293

40. Smith R, Sun Y, Garin A, Fein A, Sleeboom HP, Chaudri H et al (2000) Femara (letrozole) showed significant improvement in efficacy over tamoxifen as first-line treatment in postmenopausal women with advanced breast cancer. Breast Cancer Res Treat $64: 27$

41. Bonneterre J, Thurlimann BJK, Robertson JFR (1999) Preliminary results of a large comparative multi-centre clinical trial comparing the efficacy and tolerability of Armidex (Anastrozole) and Tamoxifen (TAM) in postmenopausal women with advanced breast cancer (ABC). Eur J Cancer 35(Suppl-4):S313

42. Vergote I, Bonneterre J, Thurlimann B, Robertson J, Krzakowski M, Mauriac L et al (2000) Randomised study of anastrozole versus tamoxifen as first-line therapy for advanced breast cancer in postmenopausal women. Eur J Cancer 36(Suppl-4):S84-S85

43. AstraZeneca P (1999) A randomised, double-blind, doubledummy trial to compare the efficacy and safety of Arimidex (ZD1033 $1 \mathrm{mg}$ daily) with tamoxifen (20 mg daily) as first-line therapy for advanced breast cancer in postmenopausal women
(1033IL/0027). Trial Report. http://www.astrazenecaclinicaltrials. com/_mshost2715844/content/content/resources/media/2958892/ 1033il_0027.pdf

44. AstraZeneca P (1999) A randomized, double-blind trial to compare the efficacy and safety of anastrozole (Arimidex $1 \mathrm{mg}$ daily) with tamoxifen citrate $(20 \mathrm{mg}$ daily) as first-line therapy for advanced breast cancer in postmenopausal women (1033IL/0030). Trial Report. http://www.astrazenecaclinicaltrials.com/_mshost27 15844/content/content/resources/media/2958892/1033il_0030_ target.pdf

45. Paridaens RJ, Dirix LY, Beex LV, Nooij M, Cameron DA, Cufer $\mathrm{T}$ et al (2008) Phase III study comparing exemestane with tamoxifen as first-line hormonal treatment of metastatic breast cancer in postmenopausal women: The European Organisation for Research and Treatment of Cancer Breast Cancer Cooperative Group. J Clin Oncol 26(30):4883-4890

46. Dirix L, Piccart MJ, Lohrisch C, Beex L, Nooij M, Cameron D, et al (2001) Efficacy of and tolerance to exemestane (E) versus tamoxifen (T) in 1st line hormone therapy (HT) of postmenopausal metastatic breast cancer (MBC) patients (pts): A European Organisation for the Research and Treatment of Cancer (EORTC Breast Group) phase II trial with Pharmacia and Upjohn. Proc Am Soc Clin Oncol 20:29a

47. Maung K (2001) Randomized phase II trial comparing exemestane to tamoxifen for first-line hormonal therapy of postmenopausal patients with metastatic breast cancer. Clin Breast Cancer 2(2):110-112

48. National Cancer Institute, Paridaens R (1996) Phase II/III randomised study of first-line hormonal therapy with exemestane versus tamoxifen in postmenopausal women with locally recurrent metastic breast cancer. Study NCT00002777. http://www. cancer.gov/clinicaltrials/EORTC-10951

49. Paridaens R, Dirix L, Lohrisch C, Beex L, Nooij M, Cameron D, et al (2000) Promising activity and safety of exemestane (E) as first-line hormonal therapy (HT) in metastatic breast cancer (MBC) patients (pts): final results of an EORTC rendomised phase II trial. Breast Cancer Res Treat 64:52

50. Paridaens R, Dirix L, Lohrisch C, Beex L, Nooij M, Cameron D et al (2003) Mature results of a randomized phase II multicenter study of exemestane versus tamoxifen as first-line hormone therapy for postmenopausal women with metastatic breast cancer. Ann Oncol 14(9):1391-1398

51. Paridaens R, Therasse P, Dirix L, Beex L, Piccart M, Cameron D, Cufer T, Roozendaal K, Nooij M, Mattiacci M-R (2004) First line hormonal treatment (HT) for metastatic breast cancer (MBC) with exemestane $(\mathrm{E})$ or tamoxifen $(\mathrm{T})$ in postmenopausal patients (pts) - a randomized phase III trial of the EORTC breast group. J Clinic Oncol (ASCO annual meeting proceedings (post-meeting edition), vol 22, no $14 \mathrm{~S}$ (July 15 Suppl):515. http://www.asco.org/ ASCOv2/Meetings/Abstracts?\&vmview=abst_detail_view\&conf $\mathrm{ID}=26 \&$ abstractID $=2103$

52. ClinicalTrials.gov (2008) Exemestane Compared with Tamoxifen in Treating Women with locally recurrent Metastic Breast Cancer. Randomized Phase II Study in first line hormonal treatment for metastic breast cancer with exemestane or tamoxifen in postmenopausal patients. Study NCT00002777

53. Milla-Santos A, Milla L, Portella J, Rallo L, Pons M, Rodes E et al (2003) Anastrozole versus tamoxifen as first-line therapy in postmenopausal patients with hormone-dependent advanced breast cancer: A prospective, randomized, phase III study. Am J Clin Oncol 26(3):317-322

54. Altundag K, Ibrahim NK (2006) Aromatase inhibitors in breast cancer: an overview. Oncologist 11(6):553-562

55. Berry J (2005) Are all aromatase inhibitors the same? A review of controlled clinical trials in breast cancer. Clin Ther 27(11):16711684 
56. Ferretti G, Bria E, Giannarelli D, Felici A, Papaldo P, Fabi A et al (2006) Second- and third-generation aromatase inhibitors as firstline endocrine therapy in postmenopausal metastatic breast cancer patients: a pooled analysis of the randomised trials. $\mathrm{Br} \mathrm{J}$ Cancer 94:1789-1796

57. Perez CR, Alberola C, V, Calabresi F, Michel RT, Santos R, Delozier T, et al (1994) Comparison of the selective aromatase inhibitor formestane with tamoxifen as first-line hormonal therapy in postmenopausal women with advanced breast cancer. Ann Oncol 5(Suppl):24

58. Thurlimann B, Beretta K, Bacchi M, Castiglione-gertsch M, Goldhirsch A, Jungi WF et al (1996) First-line fadrozole HCI (CGS 16949A) versus tamoxifen in postmenopausal women with advanced breast cancer. Ann Oncol 7(5):471-479

59. Panageas KS, Ben-Porat L, Dickler MN, Chapman PB, Schrag D (2007) When you look matters: the effect of assessment schedule on progression-free survival. J Natl Cancer Inst 99(6):428-432

60. Carroll KJ (2007) Analysis of progression-free survival in oncology trials: some common statistical issues. Pharm Stat 6(2):99-113

61. EMEA (2008) Appendix 1 to the guideline on the evaluation of anticancer medicinal products in man (CHMP/EWP/205/95
REV.3) methodological considerations for using progression-free survival (PFS) as primary endpoint in confirmatory trials for registration. EMEA

62. Chakravarty A, Sridhara R (2008) Use of progression-free survival as a surrogate marker in oncology trials: some regulatory issues. Stat Methods Med Res 17(5):515-518

63. Song F, Loke YK, Walsh T, Glenny AM, Eastwood AJ, Altman DG (2009) Methodological problems in the use of indirect comparisons for evaluating healthcare interventions: survey of published systematic reviews. Br Med J 338:B1147

64. Kataja V, Castiglione M (2008) Locally recurrent or metastatic breast cancer: ESMO Clinical Recommendations for diagnosis, treatment and follow-up. Ann Oncol 19(Supp 2):ii11-ii13

65. National Comprehensive Cancer Network (2009) Clinical practice guidelines in oncology. 2009. Report No.: V.1.2010. http://www.ncen.org

66. National Institute for Health and Clinical Excellence (2009) Hormonal therapies for the adjuvant treatment of early oestrogenreceptor-positive breast cancer. NICE technology appraisal guidance 112. Report No.: Issue date: November 2006. Review date: June 2009. http://www.nice.org.uk/nicemedia/live/11598/ 33642/33642.pdf 